\title{
How to Maximize the Outcomes of Cochlear Implantation in Common Cavity and Cochlear Aplasia With Dilated Vestibule, the Most Severe Inner Ear Anomalies?
}

\author{
Bong Jik Kim ${ }^{1}$ (D) Byung Yoon $\mathrm{Choi}^{2}$ (D) \\ ${ }^{1}$ Department of Otolaryngology-Head and Neck Surgery, Chungnam National University Sejong Hospital, Chungnam National University \\ College of Medicine, Sejong; ${ }^{2}$ Department of Otorhinolaryngology-Head and Neck Surgery, Seoul National University Bundang Hospital, \\ Seoul National University College of Medicine, Seongnam, Korea
}

Managing patients with inner ear malformations, including common cavity (CC) or cochlear aplasia with dilated vestibule (CADV), with severe to profound sensorineural hearing loss poses a substantial clinical challenge since inner ear malformations have traditionally been considered relative or absolute contraindications to cochlear implantation (CI) and their etiologies have remained largely unknown with some exceptions [1,2]. Nonetheless, CI has been generally considered a valid option for CC despite inconsistent outcomes [3]. Satisfactory short-term outcomes of CI for cochlear aplasia have also been anecdotally reported at the case report level $[4,5]$, although CADV has been traditionally viewed as a contraindication to CI.We are thus faced with the question: what accounts for these contradictory results of $\mathrm{CI}$ for $\mathrm{CC} / \mathrm{CADV}$ ?

First, the status of the common cochleovestibular nerve or cochlear nerve can be responsible for variable outcomes in cases of CC/CADV. The fibers of the common cochleovestibular nerve or auditory tissues are thought to be distributed along the cavity wall of these anomalies [6]. This has been clinically and electrophysiologically supported by a recent observation that a full-band straight electrode clearly outperformed modiolar hugging electrodes in eliciting electrically evoked compound action potential (ECAP) responses in CADV [7]. Specifically, Yamazaki et al. [8]

- Received February 6, 2022

Accepted February 9, 2022

- Corresponding author: Byung Yoon Choi

Department of Otorhinolaryngology-Head and Neck Surgery, Seoul

National University Bundang Hospital, Seoul National University College of

Medicine, 82 Gumi-ro 173beon-gil, Bundang-gu, Seongnam 13620, Korea

Tel: +82-31-787-7406, Fax: +82-31-787-4057

E-mail: choiby2010@gmail.com evaluated the spatial distribution of auditory neuronal tissue in CC deformities by electrical auditory brainstem response recording and suggested that the auditory neuronal tissue is distributed in the anteroinferior part of CC deformities. Successful stimulation by $\mathrm{CI}$ requires a wide distribution of the auditory tissues, a prerequisite for which is that the cochleovestibular nerve at the level of the internal auditory canal is normal or at worst mildly hypoplastic.

Next, positioning the electrode to allow maximum contact of the $\mathrm{CI}$ electrode with the inner wall appears to be crucial for successful CI in CC/CADV.Very recently, Bae et al. [9] reported that proper contact of the electrode with the inner wall is more likely to be important for CI success in cases of CC/CADV than appropriate placement of just the electrode tip. In their study, one subject whose CI electrode failed to contact the inner wall of the CC cavity showed only limited performance compared to others whose electrodes were in sufficient contact with the periphery of the cavity, albeit with some of the electrode tips being placed in the internal auditory canal or anterior semicircular canal [9]. In line with this, Lee and Choi [7] proposed advantages of ECAP-based positioning of full-band straight electrodes in $\mathrm{CC} / \mathrm{CADV}$ cases. Indeed, they proved that a different position of the full-band straight electrode can lead to a different degree of ECAP response in the same CADV cavity. On this basis, they argued that the degree of contact with the inner wall of the cavity is the main prognostic parameter for successful CI. Further, a lower maximum comfortable level and better behavioral outcomes were observed in relation to a shorter distance between the inner wall of the CC/CADV cavity and the electrode [10].

Taken together, achieving the maximum $\mathrm{CI}$ outcomes in $\mathrm{CC} /$

Copyright () 2022 by Korean Society of Otorhinolaryngology-Head and Neck Surgery.

This is an open-access article distributed under the terms of the Creative Commons Attribution Non-Commercial License (https://creativecommons.org/licenses/by-nc/4.0) which permits unrestricted non-commercial use, distribution, and reproduction in any medium, provided the original work is properly cited. 
CADV depends on the presence of an intact or at worst mildly hypoplastic cochleovestibular nerve and proper positioning of the electrode ensuring the best contact with the inner wall of the cavity, which could sometimes be assisted by ECAP measurements.

\section{CONFLICT OF INTEREST}

No potential conflict of interest relevant to this article was reported.

\section{ORCID}

Bong Jik Kim https://orcid.org/0000-0002-6384-2171

Byung Yoon Choi https://orcid.org/0000-0001-5125-2118

\section{AUTHOR CONTRIBUTIONS}

Conceptualization: BYC. Writing-original draft: BJK, BYC. Writing-review \& editing: BYC.

\section{REFERENCES}

1. Sennaroglu L, Bajin MD. Classification and current management of inner ear malformations. Balkan Med J. 2017 Sep;34(5):397-411.

2. Kim BJ, Jeon H, Lee SY, Yi N, Han JH, Seo GH, et al. Major contribution of GREB1L alterations to severe inner ear malformation largely in a non-mendelian fashion. Clin Exp Otorhinolaryngol. 2022 Feb; 15(1):115-8.

3. Brotto D, Avato I, Lovo E, Muraro E, Bovo R, Trevisi P, et al. Epidemiologic, imaging, audiologic, clinical, surgical, and prognostic issues in common cavity deformity: a narrative review. JAMA Otolaryngol Head Neck Surg. 2019 Jan;145(1):72-8.

4. Jeong SW, Kim LS. Cochlear implantation in children with cochlear aplasia. Acta Otolaryngol. 2012 Sep;132(9):910-5.

5. Alhabib SF. Audiological and speech performance after cochlear implantation in cochlear aplasia deformity. Cureus. 2021 Jul;13(7): e16654.

6. Graham JM, Phelps PD, Michaels L. Congenital malformations of the ear and cochlear implantation in children: review and temporal bone report of common cavity. J Laryngol Otol Suppl. 2000 Mar; 114(S25):1-14.

7. Lee SY, Choi BY. Potential implications of slim modiolar electrodes for severely malformed cochleae: a comparison with the straight array with circumferential electrodes. Clin Exp Otorhinolaryngol. 2021 Aug;14(3):287-94.

8. Yamazaki H, Naito Y, Fujiwara K, Moroto S, Yamamoto R, Yamazaki $\mathrm{T}$, et al. Electrically evoked auditory brainstem response-based evaluation of the spatial distribution of auditory neuronal tissue in common cavity deformities. Otol Neurotol. 2014 Sep;35(8):1394-402.

9. Bae SH, Choi J, Choi JY. Cochlear implants for patients with common cavity deformities and the impact of electrode positioning. Clin Exp Otorhinolaryngol. 2022 Feb;15(1):77-83.

10. Wei X, Zhang H, Lu S, Yang M, Chen B, Chen J, et al. Application of multiplanar volume reconstruction technique for the assessment of electrode location and analysis of the correlation to cochlear programming and performance in common cavity deformity. Front Neurol. 2022 Jan;12:783225. 